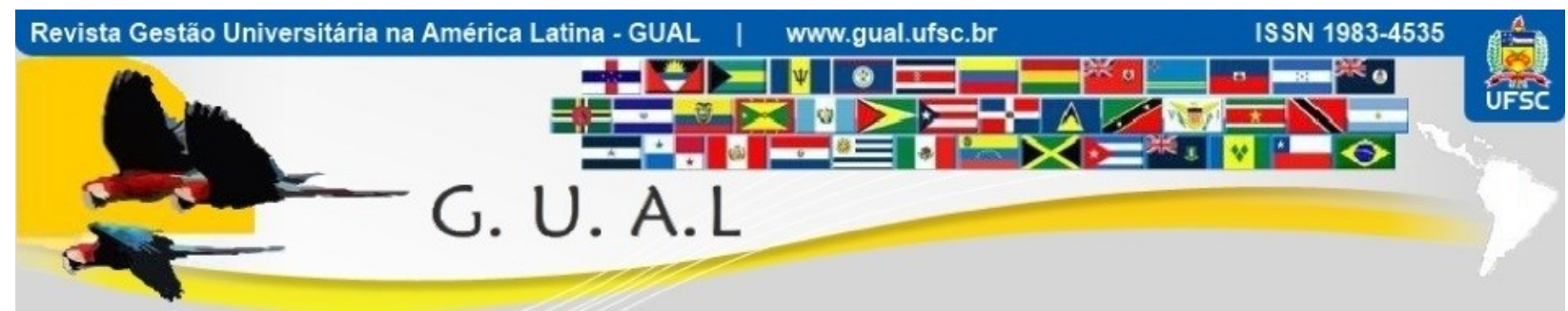

DOI: http://dx.doi.org/10.5007/1983-4535.2013v6n3p86

\title{
O CAMPO CIENTÍFICO NA PERCEPÇÃO DE DOCENTES DE UMA UNIVERSIDADE: ENTRE REGRAS E ESTRATÉGIAS DE SOBREVIVÊNCIA
}

\author{
THE SCIENTIFIC FIELD IN THE PERCEPTION OF TEACHERS OF A \\ UNIVERSITY: BETWEEN RULES AND STRATEGIES FOR SURVIVAL
}

Juliana Cristina Teixeira, Doutoranda Universidade Federal de Minas Gerais - UFMG julianacteixeira@yahoo.com.br

Mônica Carvalho Alves Cappelle, Doutora Universidade Federal de Lavras - UFLA edmo@dae.ufla.br

Denis Alves Perdigão, Doutorando Universidade Federal de Minas Gerais - UFMG denis.perdigao@globo.com

Luiz Marcelo Antonialli, Doutor Universidade Federal de Lavras - UFLA $\underline{\text { lmantonialli@uol.com.br }}$

Recebido em 17/maio/2013

Aprovado em 21/agosto/2013

Sistema de Avaliação: Double Blind Review

Esta obra está sob uma Licença Creative Commons Atribuição-Uso. 


\title{
RESUMO
}

O contexto da pesquisa científica pode ser considerado um campo social, como um universo relativamente autônomo de relações sociais específicas. Se for considerada a concepção de Bourdieu $(1989,1996,2004 a)$ em relação aos campos sociais, se pode dizer que a sociedade é composta por vários campos diversos, vários espaços que possuem uma autonomia relativa, com regras e características próprias de funcionamento. Cada um desses campos funciona, segundo o autor, como microcosmos sociais que possuem valores, objetos e interesses específicos. Nesse contexto, o objetivo do presente trabalho é analisar a percepção dos docentes acerca das (1) regras e normas do campo científico e acerca das (2) estratégias que empreendem para atuar ou sobreviver neste meio. Quanto aos fins, a pesquisa é descritiva e a abordagem utilizada foi qualitativa. Os sujeitos da pesquisa foram docentes da Universidade Federal de Lavras, localizada no interior de Minas Gerais. A coleta de dados se deu por meio de entrevistas pessoais conduzidas por meio de roteiros semi-estruturados. As principais regras do meio científico observadas pelos docentes foram: publicar, relacionar-se e obter recursos. Vários entrevistados se vêem desenvolvendo estratégias para sobreviver neste campo, as quais se relacionam diretamente ao atendimento a tais regras. A busca por reconhecimento dos próprios pares dentro do campo se mostrou significativa, assim como a busca por elementos de distinção. Destaca-se, com o estudo, a demonstração do contexto de pressão vivenciado pelos docentes entrevistados, como a significativa necessidade de publicação.

Palavras-chave: Campo científico. Docentes. Universidade. Regras. Estratégias.

\begin{abstract}
The context of scientific research can be considered a social field, as a relatively autonomous universe of specific social relations. If we take the concept of Bourdieu (1989, 1996, 2004a) in relation to social fields, one can say that society is composed of several diverse fields, multiple spaces that have a relative autonomy, with its own characteristics and rules of operation. Each of these fields works, according to the author, such as social microcosms that have values, objects and interests. In this context, the objective of this paper is to analyze the perception of teachers about (1) the rules and standards of scientific field and about (2) strategies they use to act or survive in this environment. As for the purpose, the research is descriptive and qualitative approach was used. The subjects were teachers at the Federal University of Lavras, located in Minas Gerais, Brazil. Data collection was through personal interviews conducted through semi-structured script. The main rules of the scientific field observed by teachers were: publish, interact and get resources. Several interviewees see themselves developing strategies to survive in this field, which directly relate to the care of such rules. The search for recognition of peers within the field was significant, such as the search for elements of distinction. It stands out, with the study, the context of pressure experienced by the teachers interviewed, such as the significant need for publication.
\end{abstract}

Keywords: Scientific Field. Teachers. University. Rules. Strategies. 


\section{INTRODUÇÃO}

O contexto da pesquisa científica, que é apenas um dos elementos integrantes do setor de ciência e tecnologia de um país (UNITED NATIONS EDUCATIONAL, SCIENTIFIC AND CULTURAL ORGANIZATION - UNESCO, 1979) pode ser considerado um campo social, como um universo relativamente autônomo de relações sociais específicas. Ao buscar uma teoria que pudesse empreender a dinâmica existente no campo científico da pesquisa, ao mesmo tempo permitindo uma visão intermediária entre a estrutura e a agência (a capacidade inventiva dos agentes), a teoria do campo de Bourdieu (1989) foi considerada adequada para a apreensão das relações sociais estabelecidas. Nesse sentido, o objetivo do presente trabalho é analisar a percepção dos docentes acerca das (1) regras e normas do campo científico e acerca das (2) estratégias que empreendem para atuar ou sobreviver neste meio.

Ouvir os docentes a respeito de suas escolhas estratégicas e do modo como percebem uma intermediação entre a estrutura e a agência do campo estudado permite que se dê voz a indivíduos que são chave para o processo de desenvolvimento científico e tecnológico de um país, revelando suas possíveis angústias, pressões e maneiras como lidam com as mesmas. Tais informações podem ser tanto utilizadas para um simples conhecimento mais detalhado desses indivíduos, como também para possíveis intervenções nas regras e jogos do sistema, que possam propiciar um ambiente de pesquisa o mais adequado possível, tanto em termos de produtividade, quanto de benefícios individuais para esses indivíduos que se dividem entre atividades de ensino, pesquisa e, em alguns casos, de extensão.

No que tange a presente pesquisa, se poderia dizer que os condicionamentos sociais exteriores seriam representados pelas regras ou condições estruturais presentes em um campo científico, aos quais os pesquisadores de certa forma estariam submetidos. Por sua vez, as subjetividades dos agentes influenciariam a capacidade que cada um teria, diante das dadas condições, de efetuar escolhas e desenvolver estratégias dentro do contexto da pesquisa.

\section{A TEORIA DO CAMPO DE BOURDIEU}

Bourdieu (1989) define campo como sendo um universo relativamente autônomo de relações específicas, como um espaço estruturado com regras próprias de funcionamento e também com suas próprias relações de força. Para o autor, a sociedade possui vários campos que diferem entre si, pois são espaços que contam com uma autonomia relativa. Nesses campos, há características e regras que lhes são particulares (BOURDIEU, 1996). Sendo 
assim, tratam-se de microcosmos sociais com valores, objetos e interesses específicos, que chamamos de capitais (BOURDIEU, 2004a).

Os campos, de acordo com a perspectiva de Bourdieu, possuem tanto propriedades universais quanto características próprias. As propriedades universais seriam o habitus, a estrutura, a doxa ${ }^{1}$ - um senso comum ou opinião consensual - e $n o m o s^{2}$ - as leis que regem o campo e que regulam a luta de forças existente (THIRY-CHERQUES, 2006). Além disso, no campo há "coisas que se faz e que se faz porque se fazem e na verdade sempre se fez assim" (BOURDIEU, 2001a, p. 123). Já as características próprias do campo estariam relacionadas com os tipos de capitais específicos a cada campo, englobando tanto bens econômicos, quanto culturais, sociais e simbólicos (THIRY-CHERQUES, 2006).

Mais especificamente, a relação que se estabelece entre campo e habitus se dá na medida em que (1) o campo é formado por agentes dotados de um mesmo habitus; (2) o campo estrutura o habitus; e (3) o habitus constitui o campo (BOURDIEU, 2009a). Ainda, "o habitus é a internalização ou incorporação da estrutura social, enquanto campo é a exteriorização ou objetivação do habitus" (VANDENBERGHE, 1999, p. 49, tradução nossa). A delimitação de um campo se dá justamente pelos valores ou formas de capital que lhe sustentam (THIRY-CHERQUES, 2006). Pois são os interesses específicos e também os investimentos econômicos e psicológicos dos agentes que determinam a existência de um campo e a demarcação de seus limites (BOURDIEU, 2004a).

Bourdieu buscou um conceito que fizesse com que as estruturas sociais deixassem de ser vistas como externas e independentes dos indivíduos e passassem a ser abordadas como um conjunto de ações e relações do mundo social. Nessa perspectiva, a relação social entre os indivíduos seria também uma relação de crenças, valores e idéias aprendidas por eles ao longo de suas vidas (ROSA, 2007). Bourdieu chamou de habitus esse conjunto de comportamentos aprendidos e estruturadores da ação. O habitus acaba constituindo a forma com que o indivíduo percebe, julga e valoriza o mundo. Vale ressaltar que suas disposições não são mecânicas e nem mesmo determinísticas, são plásticas e flexíveis, podendo ser fortes ou fracas (THIRY-CHERQUES, 2006).

\footnotetext{
${ }^{1}$ A doxa substitui, de forma mais clara e precisa, o que a teoria marxista chama de ideologia ou falsa consciência. A doxa é aquilo sobre o que todos os agentes estão de acordo, contemplando tudo o que é admitido como sendo assim mesmo: os sistemas de classificação, o que é interessante ou não, o que é demandado ou não (BOURDIEU, 2004a).

${ }^{2} \mathrm{O}$ nomos "congrega as leis gerais, invariantes, de funcionamento do campo. [...] Todo campo, como produto histórico, tem um nomos distinto" (THIRY-CHERQUES, 2006, p. 37).
} 
Em relação ainda ao habitus, pode-se dizer que, de acordo com a perspectiva de Bourdieu, o conhecimento das regras e disposições do campo, ou o que se poderia chamar de leis, faz com que os agentes possam transformar conforme seus desejos o resultado dos mecanismos. Ou seja, pode-se afirmar que Bourdieu retomaria uma afirmação de Engels, que seria a de que "a liberdade não reside numa independência sonhada em relação às leis da natureza (aqui a sociedade), mas no conhecimento dessas leis e na possibilidade dada por aí mesmo de colocá-las em operação para fins determinados” (QUINIOU, 1996, p. 59).

Considerando que, para Bourdieu, o agente só se integra em um campo se agir com as armas desse próprio campo; e que é este campo que define a estrutura do jogo, vale aqui discutir algumas características ou propriedades do que seria o campo científico na visão do autor. Para ele, o campo científico é

[...] o lugar e o espaço de uma luta concorrencial. O que está em luta são os monopólios da autoridade científica (capacidade técnica e poder social) e da competência científica (capacidade de falar e agir legitimamente, isto é, de maneira autorizada e com autoridade) que são socialmente outorgadas a um agente determinado (BOURDIEU, 2003, p. 112, grifo do autor).

E no qual os agentes teriam, nesse caso, capacidades desiguais para se apropriar do produto de trabalhos científicos. Nesse campo, a dinâmica de conhecimento e reconhecimento se torna fundamental, dado que o reconhecimento é um elemento considerado fundamental por Bourdieu (2001b) para que o poder se exerça dentro dos campos sociais. Dessa forma, Bourdieu (2003) afirma que o universo da ciência é um campo social como outro qualquer, caracterizado por lutas, estratégias, interesses, relações de força e lucros, os quais se revestem, contudo, de formas específicas.

Assume-se que os agentes possam "fazer" os fatos científicos e, em parte, também o campo científico. Por exemplo, os pesquisadores podem definir quais serão os objetos de pesquisa e as questões importantes em um dado momento (BOURDIEU, 2004b). Contudo, suas possibilidades ou impossibilidades de ação, sua capacidade "de submeter as forças do campo aos seus desejos são proporcionais à sua força sobre o campo, isto é, ao seu capital de crédito científico ou, mais precisamente, à sua posição na estrutura da distribuição do capital" (BOURDIEU, 2004b, p. 25).

Falando em capital, os capitais científicos reconhecidos por Bourdieu (2004b) são o capital científico puro - que é aquele adquirido por meio de contribuições do pesquisador ao progresso da ciência, como as publicações, sendo que tal capital pode conferir a este 
pesquisador um crédito específico dentro do campo - e o capital científico político ou institucional - que é adquirido por meio de estratégias políticas, como o exercício de atividades como participações em comissões decisórias, bancas de teses e de concursos, cerimônias ou reuniões, que se relaciona, por exemplo, à ocupação de cargos políticos e que pode, por sua vez, conferir ao pesquisador o que se chama de crédito político.

Discutidos brevemente os conceitos que norteiam o presente estudo, segue-se, então, à apresentação dos procedimentos metodológicos adotados para a pesquisa.

\section{PROCEDIMENTOS METODOLÓGICOS}

Quanto aos fins, a pesquisa é descritiva, já que tem como objetivo descrever as características de um determinado fenômeno (GIL, 1989). A abordagem utilizada foi a qualitativa, e os sujeitos da pesquisa são docentes/pesquisadores da Universidade Federal de Lavras (UFLA) que tiveram projetos aprovados em editais da Fundação de Amparo à Pesquisa no Estado de Minas Gerais (FAPEMIG) do ano de 2009, sendo essa uma agência de fomento ao desenvolvimento científico e tecnológico de Minas Gerais. A UFLA é uma universidade pública localizada no interior de Minas Gerais, Brasil, que foi fundada em 1908, com o nome Escola Agrícola de Lavras, depois Escola Superior de Agricultura de Lavras (ESAL) (UFLA, 2010a), até se tornar UFLA, por meio da Lei 8.956 de dezembro de 1994. A universidade oferece, atualmente, 28 cursos de graduação (UFLA 2010b), cursos de pós-graduação Lato Sensu e 20 programas de Mestrado e Doutorado (UFLA, 2010c). Trata-se, assim, de uma universidade que atua significativamente tanto no ensino de graduação quanto de pósgraduação.

A coleta de dados, realizada de outubro a dezembro de 2010 , se deu por meio de entrevistas pessoais com uma amostra de docentes da universidade que tiveram projetos de pesquisa aprovados nos referidos editais na condição de coordenadores. Quanto às entrevistas, que estão dentre as técnicas qualitativas utilizadas por Bourdieu (THIRY-CHERQUES, 2006), foram realizadas por meio de roteiros semi-estruturados, contendo tópicos a serem abordados em um processo flexível de condução, que permitisse adequação às especificidades do entrevistado.

Foram realizadas 12 entrevistas com duração média de 40 minutos. A amostra foi selecionada aleatoriamente, sendo o universo constituído pelos coordenadores de projetos selecionados pela FAPEMIG em 2009 na UFLA (92 projetos). O número de entrevistados se justifica pela natureza qualitativa de abordagem, pela necessidade de se analisar com mais 
detalhamento as entrevistas de cada coordenador, e pelo fato de que esta pesquisa não visa generalizar seus resultados. A análise dos dados foi feita por meio da análise de conteúdo.

\section{PERCEPÇÃO DOS DOCENTES ACERCA DAS RELAÇÕES ENTRE SUAS ESCOLHAS NA PESQUISA E AS REGRAS DOS EDITAIS E DO MEIO CIENTÍFICO: A PERCEPÇÃO DA AGÊNCIA SOBRE A ESTRUTURA DO CAMPO CIENTÍFICO}

De modo específico, os pesquisadores explicitaram suas percepções, em primeiro lugar, sobre o campo científico, no que se refere a possíveis regras de funcionamento do mesmo, ou seja, o que era requisito para que se mantivessem dentro do campo da ciência e também quais as condições acreditavam ser importantes para que a carreira de pesquisador seja consolidada dentro do meio. Em segundo lugar, analisou-se qual era a percepção que os mesmos possuíam sobre estar desenvolvendo estratégias para atuar ou sobreviver dentro desse meio.

\subsection{PERCEPÇÕES SOBRE AS REGRAS DO CAMPO CIENTÍFICO}

Buscou-se analisar a percepção dos docentes acerca das regras de funcionamento do meio científico ao qual pertencem, considerando que "o direito de entrada no campo é dado pelo reconhecimento de seus valores fundamentais, pelo conhecimento das regras do jogo" (THIRY-CHERQUES, 2006, p. 40). Quando questionados sobre as regras que conseguem perceber, observa-se que os docentes enfatizam preponderantemente a necessidade de publicações e, principalmente, publicações de qualidade em veículos de comunicação científica. O Pesquisador 6, por exemplo, disse "[...] eu tenho que publicar, e essa publicação é o resultado, mas é o que abre portas para que eu tenha mais possibilidades de aumentar a carreira de pesquisador [...]. A Pesquisadora 11 também enfatiza tal necessidade:

O prestígio hoje é publicar em revistas Qualis A, e não é fácil em função da demanda de trabalho que a gente tem, é muito difícil. O congresso, você tem o prazo que é limitado, aí você corre, vira a noite e faz. Agora a revista, você fica, eu vou fazer depois, aí você acaba não fazendo. Eu acho que essa sobrecarga de trabalho prejudica muito nesse aspecto. (PESQUISADORA 11)

Observa-se que a entrevistada, assim como outros docentes, se sente pressionada para que o nível e a qualidade de publicações sejam adequados. O relato do Pesquisador 7, por exemplo, demonstra nitidamente o contexto de pressão em que estes docentes admitem viver, bem como uma possível estratégia de subversão ou de crítica ao sistema: 
Olha... fazer pesquisa hoje em dia é maluquice. Eles colocam pra gente um objetivo que é muito alto... sabe? Eles querem sempre que a gente produza em um ritmo muito elevado. Pra mim, mais importante que produzir muito é produzir bem. Eu fico mais satisfeito quando eu sei que alguém citou meu artigo do que quando eu sei que eu publiquei o artigo sabe? Isso também é mais importante... então eu acho que regras... eu acho que esta questão toda aí...como é que se entra no sistema...como é que se sai do sistema...e como se mantém né...eu acho que o sistema tá cada vez mais uma loucura acadêmica que é produzir em quantidade e...e realmente fica meio...você acaba percebendo que as pessoas estão publicando em uma quantidade que é impossível de assimilação do conhecimento dela mesma. Como é que uma pessoa consegue publicar 10 artigos... 12 artigos... igual um ano que eu publiquei 8 artigos... isso me custou alguma coisa... entendeu? E manter esse ritmo certamente vai me custar alguma coisa... vai me custar outras coisas... eu só vou viver e respirar isso. E aí vou perder qualidade de integração no meio em que eu vivo [...]. A coisa tem que ser natural [...], não pode ser uma pressão do sistema. (PESQUISADOR 7)

Pelo relato, verifica-se como o Pesquisador 7, assim como outros entrevistados, reconhece estar, no âmbito científico, dentro de uma dinâmica de existência de regras que devem ser observadas. As entrevistas demonstraram um contexto de forte pressão para a competição e também meritocracia. Mas a fala do Pesquisador 7 expressa não só a pressão que admite viver para atender às regras desse campo científico, como também sua possibilidade de resistir às mesmas. O Pesquisador 7 é um pesquisador que se preocupa não só com seu nível de publicação, considerado por ele uma regra para se integrar no sistema, mas também com seu nível de integração dentro do meio científico. Ou seja, ele pretende um equilíbrio entre o atendimento da regra publicar e sua necessidade de relacionamento dentro do meio.

A importância do relacionamento referido pelo Pesquisador 7 também pode ser considerada uma regra de funcionamento do meio percebida pelos entrevistados. $\mathrm{O}$ Pesquisador 7 considera a importância do relacionamento preponderantemente como desejo pessoal dentro do meio. Mas vários entrevistados citaram a necessidade de relacionamento com os pares propriamente como uma regra do meio científico, o que repercute diretamente na necessidade do estabelecimento de parcerias entre os mesmos, o que reforça a importância de uma habilidade política:

[...] a regra básica é ter dentro da minha área de atuação, primeiro, contato com outros pesquisadores que lidam naquele segmento [...] isso é imprescindível, [...] a sua capacidade pra trabalhar em grupo... a sua habilidade de adentrar nesses grupos né [...] (Pesquisador 9).

Eu acho importante essa questão do relacionamento com as outras pessoas, porque trabalhar sozinho é muito difícil. Então, a partir desse relacionamento você consegue fazer projetos maiores... então a questão da habilidade de cognição junto a outras pessoas [...]. (Pesquisadora 11) 
Dessa forma, a regra relacionar-se se apresenta também como diretamente relacionada à regra publicar, ou seja, o estabelecimento de parcerias se torna uma estratégia para o atendimento à necessidade de publicações. Ainda em relação à regra publicar, os docentes apontam a necessidade de obtenção de recursos para a realização das pesquisas. Como a instituição dos docentes não possui, assim como ocorre no contexto das várias instituições de ensino e pesquisa do país, recursos suficientes para o financiamento das pesquisas realizadas por seus docentes, os órgãos de apoio e fomento à pesquisa ganham destaque no que se refere à viabilização de suas pesquisas. O Pesquisador 2, por exemplo, cita como regras tanto a publicação quanto obter recursos para as pesquisas, condição esta também apontada por outros entrevistados.

Regras basicamente é você correr atrás de recursos, sempre arrecadar recursos, para poder estar produzindo projetos. É uma regra que você tem que conseguir. Outra regra é publicar [...] outra regra é publicar dentro de questões éticas [...]. (PESQUISADOR 2)

[...] isso é uma regra, não tem produção não entra [...] "ah... eu não tenho produção", [...] então você tem que tentar, e batalhar e insistir [...] Tem que prestar atenção nos editais [...]. (PESQUISADORA 3)

O reconhecimento da regra obter recursos se assemelha, ainda, ao resultado obtido por Araújo (2008), ao estudar uma rede colaborativa de pesquisa, em relação à existência, como regularidade, da visão do cientista como arrecadador de recursos. $\mathrm{O}$ autor descreve que

[...] as entidades de pesquisas [...] não asseguram os fundos para custeio das pesquisas, que devem ser buscados junto aos organismos de fomento. Como consequência, há valorização da habilidade de construir alianças e conceber projetos competitivos e alinhados com os Editais e políticas das agências financiadoras. (ARAÚJO, 2008, p. 189).

Assim, verifica-se que os docentes reconhecem que, para estarem dentro do campo científico e obterem sucesso, dependem de publicações que estão diretamente relacionadas aos resultados das pesquisas que realizam e, principalmente, às condições de viabilização destas pesquisas, a qual pode ser proporcionada pela aprovação de projetos em editais de órgãos de fomento. Mais especificamente, a publicação se torna o meio para um objetivo fim, que é a obtenção de prestígio e reconhecimento dentro do campo científico.

Ainda, ressalta-se que o reconhecimento da regra publicar, enquanto importante no meio científico, advém da noção de legitimidade sugerida por Bourdieu (2001b) em relação àquelas palavras que são publicadas no campo da ciência. Já que, de acordo com o autor, a crença na legitimidade se manifesta como elemento fundamental para se entender a 
cumplicidade dos que estão no poder. Pois "o que faz o poder das palavras e das palavras de ordem, poder de manter a ordem ou de subvertê-la, é a crença na legitimidade das palavras e daquele que as pronuncia" (BOURDIEU, 2001b, p. 15). Tal legitimidade seria, pois, obtida por meio das publicações, já que no campo científico algo que está em luta é a competência científica, enquanto "capacidade de falar e agir legitimamente, isto é, de maneira autorizada e com autoridade" (BOURDIEU, 2003, p. 112). Assim, tal autoridade seria obtida por meio da aceitação de uma produção científica por um congresso/periódico. Quanto mais renomado for o veículo de publicação, mais autoridade conferida ao pesquisador para falar legitimamente.

Adicionalmente, nesse meio, pôde-se constatar uma significativa situação de pressão por parte dos docentes. A percepção desses agentes em relação às regras de funcionamento do meio científico está situada, em grande parte, na obtenção do capital científico puro descrito por Bourdieu (2004b), determinada pelas contribuições científicas do pesquisador, tais como as publicações. A pressão para publicar se mostra tão significativa na fala dos docentes que o Pesquisador 5, ao ser simplesmente questionado se consegue descrever quais são as regras de funcionamento do meio científico, refere-se prontamente à mídia científica, e não ao meio científico, como se pode observar no seguinte relato:

\begin{abstract}
A mídia cientifica requer sua presença constante, isso requer que você publique em revistas nacionais, internacionais, de impacto, para isso você tem que ter conhecimento técnico cientifico para que você possa produzir bons trabalhos, profundos, para que a mídia cientifica possa aceitá-los, e isso é importante para que você tenha reconhecimento dos seus colegas e para que você esteja sempre na mídia. (PESQUISADOR 5)
\end{abstract}

Pelo relato do Pesquisador 5, verifica-se sua percepção de que publicar seja condição para que o pesquisador tenha reconhecimento dos pares dentro do campo científico, reconhecimento este enfatizado por Bourdieu (2003; 2004b) enquanto objetivo de pesquisadores. A expressão mídia mostra, também, uma noção de publicar próxima ao de estar em evidência, aparecer, ou ser visto pelos pares. Ainda, o relato revela a ênfase justamente ao que seria o capital científico puro, oriundo de contribuições à ciência, como as publicações (BOURDIEU, 2004b). Nesse sentido, verifica-se uma dinâmica em que as publicações se tornam um meio de legitimação. Porém, quando o pesquisador adquire certo status dentro do campo, ou possui uma habilidade política, tal como a capacidade de obter capital científico político, ele também adquire a capacidade de falar e agir legitimamente.

O Pesquisador 5 continua o relato anterior citando adicionalmente a já discutida regra relacionar-se também como condição para a obtenção do capital científico puro, reforçando 
os resultados aqui discutidos, além de citar aspectos como mérito e competitividade, que seriam inerentes ao campo científico da forma com que Bourdieu (2004a) o descreve:

\begin{abstract}
Participação em congressos... contatos em congressos... via email... via Skype, para que você possa manter o contato com pesquisadores de sua área de pesquisa... escrever livros, capítulo de livros, se manter na mídia cientifica com trabalho árduo, publicar com qualidade e em boa quantidade. Sou bolsista do CNPq e nós sabemos como é difícil hoje continuar tendo mérito e, sendo bolsista CNPq, cada vez mais a competitividade é maior [...]. (PESQUISADOR 5)
\end{abstract}

Quanto à regra publicar, cita-se também a relevância de que, de fato, tal publicação esteja agregando algo em termos de conhecimento científico:

O levantamento bibliográfico... fazer um levantamento para não estar reinventando a roda é de extrema importância, para saber o que está acontecendo dentro da pesquisa [...]. Então precisa sempre agregar uma coisa a mais naquela pesquisa, para que ela sempre venha a crescer, a contribuir, para que se torne uma pesquisa de referência. (PESQUISADOR 1)

Assim, a dinâmica de referenciar outros pesquisadores e ser também referenciado torna-se um padrão dentro do campo, o que se relaciona a um poder de caráter simbólico. A palavra referência dita pelo Pesquisador 1, assim como a palavra reconhecimento citada por vários entrevistados sugere como o fazer pesquisa se torna, assim como destacado por Bourdieu (2004a), uma dinâmica na qual está em jogo o reconhecimento daquele que está apto para falar a verdade. Reconhece-se que conseguir publicar em revistas renomadas, por exemplo, dá ao pesquisador certa distinção dentro do campo.

Como regra percebida pelos docentes, pode-se citar ainda, dentro da dinâmica de publicar, a necessidade de se trabalhar focado. Contudo, tal necessidade desponta mais como uma estratégia para atender à necessidade de publicar e obter recursos, do que propriamente uma regra. Trata-se da estratégia de especializar-se em uma temática para se tornar referência dentro da mesma.

\footnotetext{
E a gente trabalha numa linha só... eu trabalho numa linha só de lá pra cá... com essa linha de trabalho, de certa forma, eu tenho hoje reconhecimento internacional no que se refere à novidade dos meus trabalhos. Eu tenho conseguido publicar em boas revistas internacionais e tenho publicado em inglês... e tem sido um resultado de 10 , 12 anos nessa linha de pesquisa. Então, de certa forma, eu tenho trabalhado muito coerente numa linha só. (PESQUISADOR 7)
}

Assim, a necessidade de disciplina para manter o foco de trabalho, mantendo uma linha coerente de pesquisa, que permita ao pesquisador se especializar e obter mais sucesso em uma área específica foi destacada pela Pesquisadora 11. Observa-se diretamente a 
percepção desses docentes de que tal estratégia possa, de fato, trazer o reconhecimento dentro do campo:

\begin{abstract}
[...] eu conheço até um professor... que ele foi meu aluno [...], fez pós-doutorado já... então por quê? Porque ele é focado... eu só trabalho com isso, não quero nem saber do resto... precisa nem me convidar... precisa nem me falar que eu não vou. Então, e aí ele tem aquela disciplina, olha... só trabalho com isso... e ele é muito bom... ele é bom... ele é mais novo que eu. E ele é bom naquela área e essa disciplina... eu só mando pra congresso bons trabalhos... eu só publico em revistas boas... e só trabalho com esse tipo de pesquisa... outra coisa, não precisa me procurar. Então, isso aí dinamiza o trabalho dele. Ele vai ser uma pessoa reconhecida logo, logo... já é de certa forma... por quê? Por causa de focar... e às vezes a gente fica querendo trabalhar e agradar todo mundo... você acaba se penalizando. Então, uma regra importante que eu vejo... eu acho que a gente tem que focar muito... pegar seu norte e seguir aquilo ali... não dá pra ficar fazendo muita coisa não. (PESQUISADORA 11)
\end{abstract}

Essa estratégia pode representar também uma resistência frente às múltiplas exigências que o campo acadêmico impõe aos docentes/pesquisadores. Interessante observar o destaque que a Pesquisadora 11 dá ao fato de um ex-aluno seu estar hoje, aparentemente, com um status maior do que o seu próprio, fazendo ainda uma associação dessa comparação com a estratégia de trabalhar focado. A ênfase em pesquisas e publicações é também criticada pelos docentes, ou seja, alguns deles assumem um posicionamento crítico em relação às regras que reconhecem dentro do ambiente científico. O Pesquisador 7 ressalta que não é só a pesquisa a atividade importante do meio acadêmico, defendendo que:

\footnotetext{
Mas a academia acha que só o pesquisador é uma pessoa valorizada. Eu acho que se eu sou pesquisador, eu acho que eu tenho alguma coisa que me ajuda a ser pesquisador [...] eu acho que você tem que ter o perfil. Nem todos os docentes têm o perfil... tem aqueles que têm mais perfil de administração... mais perfil de ensino... e não de pesquisa. E aí? Qual é o perfil do pesquisador? Eu não sei, eu acho que a pessoa tem que ser capaz de pelo menos de ter êxito [...] o pesquisador tem que ser capaz de estabelecer uma hipótese clara, e conseguir recursos pra trabalhar com aquela hipótese até o final de forma sistemática e coerente. (PESQUISADOR 7)
}

O Pesquisador 7 chama atenção para um aspecto importante da pesquisa: os sujeitos entrevistados estão envolvidos dentro do ambiente específico de pesquisa, por estarem todos vinculados a programas de pós-graduação Stricto Sensu. Assim, suas percepções serão influenciadas por esse contexto específico, como se pode observar no seguinte trecho da entrevista da Pesquisadora 11:

Porque as regras hoje estão muito em cima de publicação e de qualidade dessa publicação. Não adianta muito... não importa se você dá aula... não importa as outras coisas... você tem que publicar... então em termos dessa área da pós [pósgraduação]. Mas graduação no geral é... é importante quem só trabalha com graduação. Mas mesmo assim, a cobrança tá sendo cada vez maior. (PESQUISADORA 11) 
Considera-se que a aula de graduação não coloque o pesquisador em evidência, não o tornando referência no meio científico. $\mathrm{O}$ relato da pesquisadora mostra uma visão crítica em relação às regras do campo. Pois há também docentes que direcionam suas carreiras para ensino e/ou extensão, e não tanto para a pesquisa em si. Dessa forma, a relevância e intensidade das regras publicar, obter recursos e relacionar-se podem ser atribuídas ao contexto específico desses sujeitos. Mais ainda, a pressão que sofrem no que se refere a pesquisas e publicações de qualidade. A necessidade de se ter um perfil específico para ser pesquisador é destacada não só pelo Pesquisador 7, mas também por outros entrevistados.

Assim que eu entrei na universidade como docente, eu já comecei a trabalhar com iniciação científica... então, pesquisa é uma coisa que quando você começa, você não para mais. Aquele profissional que para, é porque não tem perfil pra pesquisa. Mas, uma vez que você começa, você não para (PESQUISADORA 12).

Contudo, ainda que o foco destes entrevistados, em seus relatos, tenha sido a pesquisa, alguns também chamam a atenção para a não desvinculação com a missão da universidade, que seria o ensino. Ou seja, demonstram uma preocupação de que as regras e pressões para publicações e pesquisas não prejudiquem o ensino na universidade.

Olha... eu acho que é você se dedicar à pesquisa, aprovar projetos, obter recursos, publicar, mas sem deixar de lado o ensino, porque essa é a missão da universidade. Você acha que tem acontecido essa dinâmica de deixar o ensino de lado? Olha... eu acho que não, porque acaba que, quando você entra em uma universidade, você tem que se dedicar ao ensino... tem uma carga horária que você tem que cumprir... então, as duas coisas têm que andar juntas. E também não adianta você se desvincular da extensão... acho que você pode fazer projetos de pesquisa que envolvam também a extensão (PESQUISADORA 12).

[...] eu queria ter mais tempo para dedicar à vida acadêmica como professor, e tem me sobrado, eu confesso, pouco tempo em função de eu participar do programa de pós-graduação, [...]. Participo ativamente, dou todas as aulas, estou presente em sala de aula sempre, dou bastante conselho, tento ensinar realmente, tento melhorar, mas eu sinto que poderia melhorar mais (PESQUISADOR 5).

O Pesquisador 5 explicita em sua entrevista, assim como alguns docentes, uma preocupação com o futuro da universidade. Ele se mostra chateado com o fato de ser um bom professor, e já ter recebido vários sinais de reconhecimento por parte dos alunos, como títulos de professor homenageado e paraninfo de formandos (títulos estes cujas plaquetas se encontravam todas dispostas em sua sala) e não receber, em contrapartida, sequer um comunicado da universidade o parabenizando pelos feitos.

Importante ponderar, contudo, o fato de que o ensino e a pesquisa podem representar dois campos que se relacionam, estão interligados, mas que são, também, diversos. As regras do MEC - Ministério da Educação, por exemplo, direcionadas para o ensino, são diferentes 
das regras da CAPES - Coordenação de Aperfeiçoamento de Pessoal de Nível Superior, mais direcionadas para o contexto da pesquisa. Ambos os campos sociais estão dentro de um campo de poder maior, que os interliga.

Por fim, ressalta-se que todos os entrevistados tinham alguma percepção clara sobre as regras de funcionamento do meio científico. Apenas um dos entrevistados declarou não enxergar tais regras: "não, eu acho que eu não vejo muito isso de regras, eu não sei, eu não sou muito novato para falar" (PESQUISADOR 4). Entretanto, o Pesquisador 4, ao longo da entrevista, reconhece as mesmas regras que foram citadas pelos outros entrevistados: a questão da publicação em periódicos renomados, por exemplo, foi algo bastante destacado pelo mesmo. Ou seja, sua recusa em falar de regras poderia advir do fato de não reconhecer as condições de inserção no meio científico como sendo regras ou, simplesmente, ausência de vontade de falar sobre o assunto.

\subsection{PERCEPÇÕES SOBRE AS CONDIÇÕES PARA A CONSOLIDAÇÃO DA CARREIRA}

Em segundo lugar, analisou-se a percepção dos docentes acerca das condições para que a carreira de docente/pesquisador seja consolidada dentro da academia, no que se referem a possíveis habilidades, competências, produtos, processos e/ou resultados necessários, o que também se relaciona diretamente à percepção sobre as regras do meio. Como condições mais citadas pelos docentes, estão a publicação de qualidade, a capacidade de produzir resultados para a sociedade com as pesquisas, a disposição para trabalhar e enviar projetos para editais de órgãos de fomento e o exercício de uma boa influência sobre os alunos.

\footnotetext{
Então, hoje o pesquisador não é único [...] então você tem que dar aula bem para você atrair aluno [...] e tem que pesquisar bem contando com os resultados para gerar publicação. E com a publicação você é valorizado [...]. Então, se você publica bem, vai aprovar um projeto bom, vai gerar recursos e você faz outro, e a roda vai girando. (PESQUISADOR 6)
}

Assim, ao falarem sobre as condições para a consolidação da carreira, observa-se uma priorização não só da pesquisa, como também do ensino. Até porque as duas áreas se mostram vinculadas, na medida em que, como relatou o Pesquisador 6, o ensino atrai alunos para a colaboração nas pesquisas e publicações. Interessante ainda a percepção de uma dinâmica que gira em torno da pesquisa, pelo que se observa nos relatos dos docentes. $\mathrm{O}$ ensino provém pessoal para a realização da pesquisa, e esta pode gerar benefícios para a sociedade de forma direta ou indireta (o que favorece a extensão). 
De forma mais específica, podem-se observar relatos que priorizam condições relacionadas especificamente a estes três pilares da universidade:

\begin{abstract}
A gente é muito questionado por isso [condições para a carreira ser consolidada]. Ser professor é dar oportunidade, acho que a gente sempre está dando oportunidade para o aluno, porque o professor influencia, e isso reverte numa importância muito grande, que é ética e comportamento [...]. [...] como, por exemplo, o meu orientador, me influenciou demais, uma pessoa ética, [...]. Outra característica também é pesquisa com resultado, é trazer uma contribuição para a sociedade e ela espera isso, porque é ela que nos mantém aqui dentro [...] não é só [...] formação de massa pública pensante, mas também de beneficio. (PESQUISADOR 1) [ensino, pesquisa e extensão]

O principal hoje que tem é produzir material cientifico de qualidade, então publicação de resultados encontrados em periódicos reconhecidos [...] esses artigos vão ser lidos, citados e é uma forma de consolidar o pesquisador. (PESQUISADOR 2) [apenas pesquisa, bem como a relação desta com o reconhecimento e o prestígio do pesquisado]

[...] eu já mandei várias vezes pedido de bolsa de produtividade do CNPq, mas eu ainda não estou em um nível qualificado para assumir... eu preciso terminar um aluno de doutorado, e eu não tenho nenhum terminado e eu perco muito ponto... então, você tem que ser... se você pensar como é feito o edital de produtividade e pesquisa, ele assume varias áreas dentro da sua carreira, desde o ensino até sua formação e pesquisa [...]. (PESQUISADOR 6) [ensino e pesquisa, sendo que o ensino afeta a possibilidade de distinção na pesquisa].
\end{abstract}

Assim, a carreira docente na universidade exigiria uma boa atuação nos três campos: ensino, pesquisa e extensão. Contudo, trata-se de campos com regras e normas distintas. Ainda, para a consolidação da carreira de pesquisador, considera-se como condição a disposição e vontade para trabalhar. A Pesquisadora 3, que tem uma preocupação muito grande com a aprovação de projetos de pesquisa e, dessa forma, com o aproveitamento de todos os editais em que pode participar, ao ser questionada a respeito das condições para a consolidação da carreira, responde que:

Primeiro... vontade de trabalhar, porque eu já me deparei com colegas, não de departamento, mas de forma geral, e a pessoa fica lá: 'ah eu não consigo aprovar projetos', mas ela também não manda, não presta atenção ao edital, [...] então [...] com quem eu encontro, eu falo 'olha tem um projeto ai, a data é não sei quando', então é interesse, vontade de trabalhar [...]. (PESQUISADORA 3)

Ou seja, a postura do docente também é considerada como uma condição para a consolidação da carreira. Se as regras são a publicação e obtenção de recursos, a disposição para atingir tal objetivo se torna um elemento fundamental. Ainda no contexto de condições pessoais necessárias, os docentes enfatizaram bastante a capacidade e habilidade de se falar outras línguas, e de escrever dentro das normas da comunicação científica. 
Hoje em dia, ele [o pesquisador] tem que ter capacidade de falar uma segunda língua e certamente uma terceira língua. Porque não se faz hoje pesquisa inovadora se não se tem uma boa leitura do que é publicado no mundo. Então, se alguém é pesquisador hoje, e não consegue ler artigos em inglês, ele não vai conseguir. Isso é até questão básica, se alguém quer iniciar nessa área, tem que ser capaz de ler. Agora, as outras aptidões, na verdade, a gente vai aprendendo, porque não tem curso pra ser pesquisador, sabe? E aí a gente vai aprendendo na marretada mesmo... aprendendo a escrever projeto... a escrever artigo... isso significa ser capaz de comunicar com a comunidade acadêmica. [...] Mas não só dominar a língua, ele tem que dominar o protocolo de comunicação científica... porque é diferente comunicar um trabalho de extensão de um trabalho de pesquisa. É diferente a comunicação de uma revista que não é científica pra outra que é científica. A comunicação pra mim é a essência do pesquisador... isso é nível básico. [...] (PESQUISADOR 7)

Dessa forma, observa-se uma vinculação da habilidade com outras línguas não só como requisito específico e direto para o sucesso enquanto pesquisador, como também como professor. Além disso, o quesito comunicação citado pelo Pesquisador 7 é bastante adequado para se indicar a finalidade da tão citada necessidade de publicação científica.

$\mathrm{Ou}$ seja, analisando em geral as condições percebidas pelos entrevistados para a consolidação da carreira como docente e pesquisador, observa-se, como disse o Pesquisador 6, que o docente não pode ser único, pois precisa se dedicar a diferentes atividades para o sucesso na carreira. Novamente, a questão da pressão para tal dedicação se demonstra relevante no relato da maior parte dos entrevistados.

[...] eu queria ter mais tempo para dedicar à vida acadêmica como professor, e tem me sobrado, eu confesso, pouco tempo em função de eu participar do programa de pós-graduação, onde nós temos que alimentar com publicações, cada vez mais somos pressionados a publicar em revistas de alto impacto e isso demanda mais tempo, e isso aí vem me preocupando muito, porque eu confesso que eu queria ter mais tempo para me dedicar ao alunato, principalmente de graduação. (PESQUISADOR 5)

Enfim, diante de todas essas exigências e pressões sofridas, observam-se os elementos integrantes da estrutura do campo científico, na percepção destes docentes. Mais especificamente, as regras observadas permitiram uma apreensão de elementos pertencentes ao nomos e à doxa do campo estudado. O nomos seria as leis gerais que governam o campo, exatamente a noção de regras do campo científico, o que acaba refletindo também, ao pedirmos para os entrevistadores falarem, elementos da doxa do campo, que é o senso comum presente no mesmo. Quando os docentes falam, por exemplo, da importância de se publicar em periódicos de qualidade, periódicos internacionais e de se realizar pesquisas inovadoras, observam-se elementos da doxa, na medida em que esta representa o senso sob o qual todos 
os membros do campo estão de acordo, estando relacionada à determinação do "que é interessante ou não, o que é demandado ou não” (THIRY-CHERQUES, 2006, p.37).

Mais uma vez se justifica a consideração de que se observam indícios dos habitus dos docentes, embora não haja sua apreensão completa, porque o senso comum e as leis gerais do campo são também representativos do habitus. Ainda, a noção de campo de Bourdieu (1996) como sendo um espaço de autonomia relativa, com suas regras e características próprias de funcionamento, justifica o porquê se questionar, na percepção destes agentes, quais são as regras de funcionamento que conseguem perceber no meio em que vivem. A possibilidade de agência se torna um elemento fundamental para que se apreendam as percepções que tais docentes possuem acerca do campo científico. Nesse sentido, cabe questionar: estes se vêem desenvolvendo estratégias para atuar ou sobreviver no meio científico? Esta foi, pois, uma das questões norteadoras das entrevistas, cuja discussão é apresentada a seguir.

\subsection{PERCEPÇÕES SOBRE O PRÓPRIO DESENVOLVIMENTO DE ESTRATÉGIAS PARA ATUAÇÃO OU SOBREVIVÊNCIA NO MEIO CIENTÍFICO}

Quando questionados sobre o desenvolvimento de estratégias para sobreviver no meio científico, apenas três dos doze docentes entrevistados disseram não se ver desenvolvendo estratégias:

\footnotetext{
Eu acho que não é sobrevivência, é estar na pesquisa. A partir do momento em que você está sempre atualizado em artigos e periódicos da sua área, você está bem situado, você sabe o que está acontecendo, participa de eventos [...] e eu acho que isso não é sobrevivência, é estar atualizado. [...] Então não é sobrevivência, é crescimento pessoal, crescimento profissional. (PESQUISADOR 1)

O que eu almejo, visualizo, é a publicação, eu tenho que publicar, e essa publicação é o resultado, mas é o que abre portas para que eu tenha mais possibilidades de aumentar a carreira de pesquisador [...]. Mas, agora, não é uma estratégia de sobrevivência, mas eu colocaria como uma estratégia de aumentar minha carreira, pensar em publicar. (PESQUISADOR 6)

Olha... eu não acho que eu desenvolva estratégias pra sobreviver não. Acho que é trabalhar... eu faço as minhas pesquisas, faço minha parte, todo edital que eu posso participar, eu estou participando. $\mathrm{O}$ pesquisador tem que querer fazer as coisas. Acho que não é uma questão de sobreviver. (PESQUISADORA 12)
}

Vale ressaltar que, de acordo com Bourdieu (2004b), as possibilidades de estratégias dentro do campo dependem da posição ocupada pelo indivíduo dentro do mesmo. Contudo, no que se refere ao não reconhecimento de estarem desenvolvendo estratégias para atuar ou sobreviver no meio científico, observa-se que os três docentes ocupam posições relativamente distintas dentro do campo, ou seja, não é possível o estabelecimento de uma relação entre esse não reconhecimento com a posição ocupada. O Pesquisador 1 é docente da universidade há 22 
anos, pesquisador há 20 anos e possui bolsa de produtividade do $\mathrm{CNPq}^{3}$ de nível 2. Já a Pesquisadora 12, seguindo a mesma linha, porém, com um destaque maior, é docente da universidade há 14 anos, pesquisadora há 20 anos e possui bolsa de produtividade de nível 1 . Já o Pesquisador 6, em contrapartida, é docente na universidade há 4 anos, pesquisador há 6 anos e não possui bolsa de produtividade, podendo ser considerado ainda um iniciante no campo. Porém, em relação ao que seria, então, o tipo de estratégia declarado pelos mesmos (ainda que não reconhecida como estratégia), observa-se que ambos declaram as mesmas: pesquisar e publicar.

Partindo para aqueles docentes que se vêem desenvolvendo estratégias para sobrevivência no campo, estão também perfis diversos. Algumas estratégias giram em torno do aproveitamento de todos os editais no qual pode participar:

\begin{abstract}
A estratégia é sempre ter recursos, sempre ter recursos, ver os editais, quais os editais que vão atender determinadas demandas, sempre submeter a editais, editais universais, editais da FAPEMIG... planejamento é a sobrevivência com os editais, e, lógico, também, publicar a produção de pesquisa. (PESQUISADOR 2)

[...] sempre pro edital que dá para eu encaixar... eu sempre mando. Então, se tem algum projeto, eu estou em busca de financiamento, sempre pesquisando. Às vezes, o mesmo projeto... você consegue desmembrar e ser três. (PESQUISADORA 3)

Aí, foi nesse sentido, a partir do momento que eu submeti meu primeiro projeto para a FAPEMIG e fui aprovado, a gente fica com uma coisa quase que constante e sucessiva, a gente termina um projeto e vai submetendo outro, e foi assim. (PESQUISADOR 6)
\end{abstract}

Outras estratégias giram em torno da tentativa de se manter um foco em linha de pesquisa para publicação:

[risos] Então, a estratégia é mais ou menos por aí né... às vezes a gente até sabe a estratégia, já tem ela pronta, mas o difícil é operacionalizar essa estratégia em função de várias coisas. Eu estou tentando agora, no caso... nesse semestre, eu já fiz reunião com meus alunos... exatamente no sentido de focar essa questão da publicação e tentar focar uma área só. (PESQUISADORA 11)

Outras se relacionam a uma dimensão mais pessoal, como a postura a ser adotada dentro do meio:

\footnotetext{
${ }^{3}$ A bolsa de produtividade do CNPq - Conselho Nacional de Desenvolvimento Científico e Tecnológico - é uma bolsa destinada a "pesquisadores que se destaquem entre seus pares", que devem ser doutores ou ter perfil científico equivalente (MINISTÉRIO DA CIÊNCIA E TECNOLOGIA - MCT, 2009, s/p). A bolsa é dividida em três categorias: (1) Pesquisador Sênior, para quem se manteve com bolsa de produtividade categoria 1 durante 15 anos, no mínimo; (2) Pesquisador 1, para quem é doutor há 8 anos, no mínimo (sendo essa categoria dividida em 4 subcategorias (A, B, C, D) que dizem respeito a uma comparação entre os próprios pares que possuem a bolsa de categoria 1; e (3) Pesquisador 2, para quem é doutor há 3 anos, no mínimo (MCT, 2009).
} 
Às vezes, é [pela] sobrevivência mesmo, às vezes as pessoas, de acordo com a formação, ou o temperamento, ou a própria origem dentro do Brasil, as pessoas tem maneiras diferentes de enfrentar problemas. E eu, como sou uma pessoa muito franca, então eu falo o que eu penso, às vezes incomoda um pouco. Então, às vezes, pra sobreviver, eu tenho que ficar de boca fechada, não emitir a minha opinião. (PESQUISADORA 8)

Mesmo sendo uma estratégia de dimensão mais pessoal, a Pesquisadora 8 revela como sua postura está em uma intermediação entre sua vontade e o meio, não emitindo sua opinião em alguns momentos como forma de sobrevivência. Nesse sentido, a Pesquisadora 10 ressalta o fato de que a estratégia acaba sendo também uma definição individual do pesquisador: "ah... estratégia em si eu acho que cada um tem a sua... o seu delineamento de percepção [...] o que você almeja... então eu acho que é característico de cada pesquisador". Além disso, considera-se que, de acordo com a subjetividade de cada indivíduo, bem como a posição que ocupa no campo, há que se considerar que ele pode almejar algo diferente do que os outros almejam.

Já na mesma linha da reconhecida regra relacionar-se do campo científico, o Pesquisador 9 ressalta, ainda, a estratégia de se manter um relacionamento adequado com os pares dentro do meio:

\begin{abstract}
Assim, sem dúvida nenhuma... [a estratégia é] a participação em eventos, em congressos, em simpósio, mantendo contato permanente com os pesquisadores que militam naquela área, isso é importantíssimo. Os trabalhos em parceria... então, são estratégias que a gente vem propondo pra se inserir, pra se manter mesmo dentro desse meio. (PESQUISADOR 9)
\end{abstract}

Pode-se dizer que tal relacionamento seja um aspecto importante para a garantia do reconhecimento do pesquisador por seus pares. Ou seja, é um meio para que tais pares conheçam e reconheçam suas contribuições para a ciência, na medida em que este relacionamento leva ao conhecimento da produção alheia.

Mais uma vez, a situação de pressão vivenciada pelos docentes fica enfatizada ao discorrerem sobre as estratégias que desenvolvem para sobreviver no campo:

Eu me vejo a todo o momento, a todo instante [desenvolvendo estratégias], minha cabeça fica girando sem parar, eu critico meu trabalho, eu critico minhas pesquisas, eu sempre me cobro mais e mais, e isso às vezes... isso me faz mal, porque aí eu tenho que eu mesmo conversar comigo, para entender que nós temos nossos erros, ninguém é perfeito, eu estou sempre buscando algo de diferente nas minhas pesquisas, $[. .$.$] aonde eu quero chegar com as minhas pesquisas, o que fazer para$ melhorar, como eu posso mudar, e hoje penso no meu pós-doutoramento, $[\ldots]$ estou tentando, $[\ldots]$ faço curso de inglês, $[\ldots]$ às vezes eu me questiono se é essa a saída, se é isso que vai ser importante e de peso para a melhoria dos meus trabalhos ou não, [...] a todo instante eu estou [...] tentando fazer mudanças para que eu possa produzir 
uma pesquisa que [...] colabore com a sociedade, para a resolução de um [...] problema [...]. Eu me cobro como docente, [...] como estão minhas aulas, se eu estou sendo maleável, se eu estou sendo muito taxativo com o estudante, [...] se eu estou cobrando meus pós-graduandos, se eu estou sendo um bom orientador para eles, se eu estou dando oportunidade realmente para eles crescerem juntos comigo no departamento, se eu estou sendo bom pesquisador, [...] e sofro por isso. (PESQUISADOR 5)

A fala do Pesquisador 5 é extremamente adequada para se encerrar a discussão sobre as percepções dos docentes acerca das regras e estratégias a serem empreendidas dentro do campo científico. Além de demonstrar a abrangência das pressões estruturais reconhecidas por estes docentes, situadas nas mais diversas áreas, como a necessidade de pesquisa inovadora, de capacitação profissional, de relevância da pesquisa para a sociedade, de qualidade no ensino e de formação de pesquisadores; a fala demonstra como se sentem alguns entrevistados diante das regras do meio.

A dinâmica do necessário conhecimento e reconhecimento dentro do campo destacado por Bourdieu (2003) se torna fonte de angústia para estes docentes. Aqueles que desejam se integrar a uma elite de pesquisadores acabam por se submeter a tais pressões. A busca não só pelo básico para se integrar no meio, como também a busca por um "algo a mais", por prestígio e reconhecimento, se faz presente em vários relatos. Em termos operacionais, observa-se desejo de obtenção de bolsa de produtividade não só objetivando recursos para pesquisas, mas também a própria distinção no campo que tal bolsa pode representar. Entre os 12 docentes entrevistados, 4 possuem bolsa de produtividade nível 2 (pesquisadores 1, 3, 7 e 8), 3 possuem bolsa nível 1 (pesquisadores 5, 10 e 12) e 5 não possuem bolsa (2, 4, 6, 9 e 11).

Vale ressaltar que não se observaram diferenças significativas de estratégias empreendidas pelos docentes relativamente às diferentes posições ocupadas pelos mesmos dentro do campo, como sugere Bourdieu (2004b), pelo menos não no nível do discurso, que foi o único apreendido. Contudo, ainda que não tenham sido observadas distinções relevantes nas percepções sobre as regras do campo e nas estratégias empreendidas em relação à posição ocupada, os docentes reconhecem a existência de maiores dificuldades no campo para os que são iniciantes. Tal aspecto permite uma análise da percepção que os mesmos possuem sobre as condições dos novos entrantes no campo.

Se você tem um bom currículo, é porque você conseguiu captar recursos e ter publicação [...]. E é uma coisa muito... é um círculo muito fechado, e é difícil para o novo pesquisador iniciar este ciclo... é sempre muito difícil. (PESQUISADOR 7)

[...] pesquisadores que ainda não tiveram a oportunidade de produzir... nunca produziram... de alguma forma, não tem produção, embora muitas vezes estejam dispostos a produzir, mostrar trabalho, eles não tem esse... não atendem a esse pré- 
requisito, que é a produção. Eles não conseguem esse projeto pra ser aprovado, essa realmente é uma limitação que eu acho que é bastante séria. É... acho que é uma questão que poderia ser repensada. (PESQUISADOR 9)

O interessante é que, dentre os docentes que, como o Pesquisadores 7 e 9, chamaram atenção para a questão da dificuldade de inserção dos novos entrantes no campo, apenas uma pode ser considerada iniciante no campo, que é a Pesquisadora 11. Ou seja, aqueles já estabelecidos dentro do campo é que estão levantando a causa dos novos entrantes. A Pesquisadora 11 não é, especificamente, uma iniciante no campo científico, pois já é pesquisadora há 16 anos e possui um bom nível de publicação científica. Porém, se formos considerar o contexto dos entrevistados, não possui ainda bolsa de produtividade, e está na UFLA como docente há aproximadamente três anos apenas. Enquanto iniciante na instituição, relata enfrentar algumas dificuldades de inserção até mesmo no ensino. Chamando então a atenção para a dificuldade de novos entrantes em aprovar projetos de pesquisa, afirma que:

E a questão também do projeto... ah, tem que ter tantos projetos publicados, tem que ser aquilo... então, assim, separa uma elite que pode participar. Se você não é doutor, você não pode. Se você não tem tantos artigos publicados, você não pode. E isso aí atrapalha... evita que pessoas que não tenham isso possam entrar nesse grupo. Acaba sendo uma coisa meio seletista na verdade. (PESQUISADORA 11)

Porém, não só as dificuldades para inserção destes iniciantes no campo são relatadas, pois os docentes também indicam possíveis estratégias a serem adotadas por parte destes iniciantes:

[...] você tem que submeter seu projeto para o edital adequado, porque hoje os editais são muito específicos. E tem editais que são pra novos pesquisadores... e tem editais que são pra uma elite de pesquisadores. Então, se você é iniciante, não adianta você concorrer com pesquisadores que estão na elite. Então, você tem que saber o que você está fazendo. (PESQUISADORA 12)

[...] alguns editais são específicos para jovens pesquisadores e a competição é menor. (PESQUISADOR 6)

Mas o que acontece com esses professores [iniciantes], eu acho, e ate já conversei, o que eles têm que fazer, começar de alguma maneira, e eles não conseguem entrar no programa de pós porque eles não tem produção e se a gente permitir essa entrada, nosso conceito cai muito e nosso programa não vai funcionar. Então, que funcione bem, não pode abrir exceções, [...] tem uma série de regras de credenciamento. "Ah... eu não tenho produção", [...] então você tem que tentar, e batalhar... e insistir, porque não adianta, eu mandei um projeto e não foi aprovado, e eu não vou mandar nunca mais? [...]. (PESQUISADORA 3)

As estratégias giram em torno, então, da submissão de projetos de pesquisa a editais adequados com a condição e a posição ocupada pelos docentes e da disposição para sempre tentar e insistir. Observa-se que a discussão dessas estratégias possíveis e da dificuldade de inserção dos iniciantes no campo não se dá de uma forma competitiva, ou seja, não fica 
evidente, nesse caso específico, uma luta de interesses. Pois a preocupação com a possibilidade de inserção no campo de mais pesquisadores de seus próprios departamentos, para que seu programa de pós-graduação seja fortalecido, parece prevalecer em relação à natureza concorrencial do campo científico (BOURDIEU, 2003). Contudo, tal observação se atém apenas a um nível micro de discussão, pois diz respeito ao desejo de fortalecimento do próprio grupo de trabalho.

\section{CONSIDERAÇÕES FINAIS}

O objetivo do presente trabalho foi o de analisar a percepção dos docentes de uma universidade pública acerca do campo científico no qual estão inseridos e das estratégias que desenvolvem para sobreviver no mesmo. No estudo, observou-se que tais docentes conseguem perceber e conhecer as leis do campo, ou seja, quais são as regras do jogo, já que, como destaca Thiry-Cherques (2006, p. 40), o próprio "direito de entrada no campo é dado pelo reconhecimento dos seus valores fundamentais". As principais regras do meio científico observadas pelos docentes foram: publicar, relacionar-se e obter recursos. As estratégias por eles desenvolvidas para sobreviver no campo se relacionam diretamente ao atendimento a tais regras. A busca por reconhecimento dos próprios pares dentro do campo se mostrou significativa, assim como a busca por elementos de distinção, como a obtenção de bolsas de produtividade.

Destacou-se o contexto de pressão vivenciado pelos docentes/pesquisadores entrevistados, o qual reforça a necessidade de que estes mantenham um adequado nível de produtividade em termos de publicação científica e de formação de recursos humanos, principalmente. Pode-se dizer, nesse sentido, que a necessidade de publicação se insere na discutida crença na legitimidade das palavras (BOURDIEU, 2001b) dentro do campo científico.

A análise da percepção dos docentes demonstra que, embora apresentem uma visão, de certa forma, generalizada em relação ao campo científico, há também a presença de posturas diferenciadas destes docentes em relação às características do campo. Ou seja, há um compartilhamento hegemônico de ideias, percepções e estratégias. Contudo, as mesmas não são uniformes, já que, como se pressupôs, tais pesquisadores internalizam disposições e crenças de modo diferenciado. 
Relativamente à pesquisa, indicam-se implicações de caráter político e prático. Observa-se, de modo reflexivo, que as políticas públicas direcionadas para a gestão das universidades e dos órgãos vinculados à pesquisa e ao desenvolvimento tecnológico possam estar gerando um ambiente de intensa pressão aos pesquisadores. Vários relataram ainda observar o incentivo à qualidade da pesquisa em detrimento do incentivo à qualidade do ensino, o que revela denúncias sutis e insatisfações relativas à trajetória que a universidade vem traçando.

Além disso, importante ressaltar que as "regras" do campo percebidas pelos docentes são, elas próprias, na concepção teórica que aqui se adota, construções sociais. Ainda que sob um processo no qual as estruturas (e com elas, as regras do jogo) são internalizadas (o habitus), passando a orientar as ações dos indivíduos, ações estas que, de forma cíclica, influenciam, por sua vez, as estruturas (que são novamente internalizadas), reflete-se sobre a possibilidade de que o questionamento das regras existentes, já que há uma insatisfação em relação a sua intensidade, possa gerar reflexões por parte daqueles que participam diretamente da constituição dessas regras do jogo. Se há intensa pressão ou desvalorização de outros aspectos não relacionados à pesquisa, como percebem grande parte dos docentes entrevistados, por que não estimular uma reflexão aos que estão inseridos no campo? Esta é, pois, a sugestão de possíveis implicações da presente discussão. Afinal, se estes docentes se inserem no campo da pesquisa, devem admitir que "ter interesse é estar em, é participar, é admitir que o jogo mereça ser jogado e que os alvos envolvidos merecem ser perseguidos" (MISOCZKY, 2003, p. 15). Assim, precisam legitimar as leis do campo. Estar "satisfeito" com as mesmas, portanto, pode ser benéfico para o próprio jogo.

Como limitação da pesquisa, destaca-se a não apreensão direta do habitus dos pesquisadores, que é um conceito central na teoria do campo de Bourdieu (1989). Tal limitação se reveste em sugestão para futuras pesquisas, a qual seria, então, a aplicação de metodologias que permitam sua apreensão. Como uma pesquisa qualitativa que não buscou representatividade na amostra, ressalta-se que os resultados não podem ser generalizados, pois a intenção foi apreender de forma mais específica e aprofundada a percepção dos docentes da universidade escolhida.

Para finalizar, duas frases dos docentes são consideradas relevantes para sintetizar algumas questões discutidas. Em primeiro lugar, apesar do contexto de pressão vivenciado pelos indivíduos pesquisados, fica uma lição - “[...] o mais importante que eu falo pros meus 
alunos, a gente tem que ser feliz naquilo que a gente faz. Eu falo pra eles, o coração alegre deixa o rosto mais bonito" (PESQUISADOR 5) - a de que o desejo e a satisfação individual também se fazem presentes em meio a todas as pressões estruturais do campo da Ciência, ou seja, a agência se faz presente. Os indivíduos não são completamente livres, mas possuem certa liberdade dentro do campo, especialmente no que se refere aos aspectos subjetivos de sua prática social.

\section{REFERÊNCIAS BIBLIOGRÁFICAS}

ARAÚJO, U. P. Relação agência e estrutura em redes colaborativas: uma análise do Consórcio Brasileiro de Pesquisa e Desenvolvimento do Café. 2008. 268 f. Tese (Doutorado). Universidade Federal de Lavras, Lavras, 2008.

BARDIN, L. Análise de conteúdo. Lisboa: Edições 70, 2004. 223 p.

BOURDIEU, P. O poder simbólico. Lisboa: Difel, 1989. 311 p. . Razões práticas: sobre a teoria da ação. São Paulo: Papirus, 1996. 231 p. . Meditações pascalianas. Rio de Janeiro: Bertrand Brasil, 2001a. . O poder simbólico. Rio de Janeiro: Bertrand Brasil, 2001b. 322p.

. O campo científico. In: ORTIZ, R. A sociologia de Pierre Bourdieu. São Paulo: Olho D’água, 2003. $172 \mathrm{p}$.

. Questoes de sociologia. Portugal: Fim de Século, 2004a.

Os usos sociais da ciência: por uma sociologia clínica do campo científico. São

Paulo: UNESP, 2004b.

. A economia das trocas simbólicas. São Paulo: Perspectiva, 2009a, 424 p.

GIL, A. C. Métodos e técnicas de pesquisa social. São Paulo: Atlas, 1989.

MINISTÉRIO DA CIÊNCIA E TECNOLOGIA - MCT. Resolução Normativa MCT-CNPq no 009/2009 - Anexo I da RN 016/2009 - Bolsas individuais no país, de 30 de abril de 2009. Diário Oficial da União, Brasília, 30 abr. 2009. Disponível em:

$<$ http://www.cnpq.br/normas/rn_06_016_anexo1.htm>. Acesso em 02 set. 2010.

MISOCZKY, M. C. A. Implicações do uso das formulações sobre campo de poder e ação de Bourdieu nos estudos organizacionais. Revista de Administração Contemporânea, Curitiba, p. 9-30. 2003. Edição especial. 
QUINIOU, Y. Das classes à ideologia: determinismo, materialismo e emancipação na obra de Pierre Bourdieu. Actuel Marx, Paris, n. 20, 1996.

ROSA, A. R. (O) Braço Forte, (A) Mão Amiga: um estudo sobre dominação masculina e violência simbólica em uma organização militar. 2007. 355 p. Dissertação (Mestrado em Administração). Universidade Federal de Lavras, Lavras.

THIRY-CHERQUES, H. R. Pierre Bourdieu: a teoria na prática. Revista de Administração Pública, Rio de Janeiro, v.40, n. 1, p. 27-55, jan./fev. 2006.

UNITED NATIONS EDUCATIONAL, SCIENTIFIC AND CULTURAL ORGANIZATION - UNESCO. Recommendation Concerning the International Standardization of Statistics on Science and Technology. Paris: UNESCO, 1979. 202p.

UNIVERSIDADE FEDERAL DE LAVRAS - UFLA. A universidade - histórico. 2010a. Disponível em: < http://www.ufla.br/Universidade/historico.html>. Acesso em 10 nov. 2010. . Graduação - cursos. 2010b. Disponível em: <http://www.ufla.br/Graduacao/cursos. html>. Acesso em 10 nov. 2010.

. Stricto Sensu - Programas de Pós-Graduação. 2010c. Disponível em: <http://www. prpg.ufla.br/prpg2010/?page_id=79>. Acesso em 10 nov. 2010.

VANDENBERGHE, F. "The real is relational"; an epistemological analysis of Pierre Bourdieu's generative structuralism. Sociological Theory, v. 17, n. 1, p. 32-67, Mar. 1999. Disponível em: <http://www.jstor.org/pss/201926>. Acesso em 06 abr. 2010. 